\title{
The Papanicolaou Smear and the Obstetric Patient: A Simple Test with Great Benefits
}

\author{
Claire W. Michael, M.D.*
}

The Papanicolaou (Pap) smear is the most successful screening test for carcinoma in the history of medicine. Since its introduction in the early 1930s, the national death rate from cervical cancer has dropped $70 \% .^{1}$ The success of this test is mainly a result of its simplicity, low cost, and low false-negative rate. The Pap test's main benefit is the early detection of preneoplastic lesions. The Pap test is also used to diagnose several infectious agents that manifest with specific cytologic features. Hormonal evaluation based on smears of the lateral vaginal wall is another important use of the Pap test.

The obstetric patient should receive a Pap smear at her first prenatal visit as part of her initial evaluation. The cytologic findings of those smears in this particular group of women have been the subject of extensive research since the 1960s. This research has generally focused on the following areas: 1) the ability to accurately diagnose preneoplastic lesions during pregnancy in light of the numerous diagnostic pitfalls that result from the physiologic changes that occur during pregnancy;,3 2) the use of hormonal evaluation and maturity index to predict fetal status, e.g., maturation, sex, placental activity, or an inevitable abortion; ${ }^{4-6}$ and 3) the detection and significance of inflammation and infectious agents. $^{7-9}$

The incidence of squamous intraepithelial lesions (SIL) is increasing among sexually active females, especially those with sexually transmitted diseases (STD). In a study reviewing 98 pregnant and postpartum patients with abnormal Pap smears and directed biopsies, 67 were diagnosed with SIL. Of these 67, 18 had high-grade (HG) SIL and 49 had low-grade (LG) SIL. ${ }^{10}$ The most appropriate follow-up strategy for pregnant women with abnormal cervical cytology has also been the subject of extensive research. It is well-documented that cervical dysplasia diagnosed during

\footnotetext{
Department of Pathology, University of Michigan, Ann Arbor, Michigan *Correspondence to: Claire W. Michael, M.D., Department of Pathology, University of Michigan, 1500 E. Medical Center Dr., Room 2G332/Box 0054, Ann Arbor, MI 48109.

Received and accepted 16 March 1999
}

pregnancy and followed by serial Pap smears until term may not necessarily progress and on occasions may even regress. ${ }^{11-13}$ Londo et al. ${ }^{14}$ found that postpartum Pap smears provide a higher yield of endocervical cells and better prediction of dysplasia than prepartum smears. Nonetheless, this does not lessen the importance of the initial smear, since a high number of these patients may be lost to follow-up through noncompliance. ${ }^{11,14}$

Interpretation of Pap smears obtained from pregnant patients can be difficult. Knowledge of the pitfalls unique to pregnancy can minimize diagnostic errors in most cases. ${ }^{10}$ The most common pitfall is misinterpreting decidua cells for SIL. Decidua cells may mimic LGSIL, HGSIL, and carcinoma. Decidua cells that slough off the free surface of the uterus may degenerate and acquire pyknotic nuclei and orangeophilic cytoplasm and be mistaken for squamous-cell carcinoma. ${ }^{15}$ During pregnancy, endocervical glands become hyperplastic and hypertrophied, and may undergo Aria-Stella-type changes. These changes are often overdiagnosed as atypical glandular cells of undetermined significance. ${ }^{10,16}$ Even years after pregnancy, involuted decidua and trophoblasts can mimic HGSIL and lead to inappropriate treatment. $^{17}$

Based on specific cytologic criteria, the diagnoses of candida, trichomonas, herpes simplex virus, and human papilloma virus can be reliably rendered on Pap smears. ${ }^{18}$ Although Clamydia trachomatis and gonococcal species cannot be accurately diagnosed on Pap smears due to the lack of specific cytologic features, they are frequently associated with inflammatory exudate and reactive cellular changes. ${ }^{19}$ Inflammation by itself on Pap smears is not necessarily indicative of infection, and an inflammatory component is commonly seen on Pap smears from pregnant women. ${ }^{20,21}$ Unfortunately, the significance of a marked inflammatory exudate in the pregnant population has not been adequately evaluated. Since patients with sexually transmitted diseases (STD) have a higher risk of preterm delivery and fetal morbidity, it is important to evaluate whether inflammation and/or the reactive changes caused by 
inflammation on Pap smears from pregnant patients can reliably predict the presence of STD, particularly in asymptomatic patients. In this issue, Bedrossian et al. ${ }^{22}$ address this question by evaluating the significance of mucopurulent exudate on Pap smears (inflammatory cells covering more than $50 \%$ of the smear) in high-risk pregnant women. They found these patients to be at high risk for STD and pregnancy-related complications.

Bacterial vaginosis (BV) is a vaginal infection in which the normal Lactobacillus-predominant vaginal flora is replaced by Gardnerella vaginalis, Bacteroides species, Mobiluncus species, and genital mycoplasma. ${ }^{23}$ BV and STD are both risk factors for a complicated pregnancy. In this issue, Mass et al. ${ }^{24}$ demonstrate a higher incidence of chorioamnionitis and preterm delivery in patients with coccobacilli and clue cells on their initial Pap smears when compared to a control group of similar women without these changes. Gram stain and/or wet mount are traditionally the methods of choice in diagnosing BV. While a wet mount is simple and inexpensive, the literature suggests that poorly performed wet mounts may result in misdiagnosis in about one third of the cases. ${ }^{23}$ Using the Bethesda system (TBS), Pap smears with BV are typically reported as "predominance of coccobacilli consistent with shift in vaginal flora." TBS falls short of diagnosing BV, since the accuracy of this diagnosis by Pap smear has been controversial, especially when compared to the Gram stain. ${ }^{25-28}$ The limitations of the Pap smear can be attributed to the following: ${ }^{28} 1$ ) the inconsistency in the criteria used to diagnose BV, i.e., some studies rely only on the presence of clue cells, while others adhere to the criteria specified by TBS; 2) variation in specimen source; studies evaluating vaginal smears report higher sensitivity for BV than those evaluating cervical/endocervical smears; and 3) the experience and number of evaluators differ among different studies and may contribute to the variable reported sensitivity of the Pap smear when compared to the Gram stain.

To improve Pap smear sensitivity in detecting BV, it is important to further define the diagnostic features of this condition. In this issue, Prey $^{29}$ compares the ability to diagnose BV by Pap smear based on TBS criteria vs. the Gram stain. Her results reveal two important findings. First, the diagnosis of BV by Pap smear requires the presence of coccobacilli alone, not mixed with other bacterial flora. Second, the Pap smear is at least as good as, if not superior to, the Gram stain in identifying BV. She recommends applying the strict criteria described by TBS. These criteria are: 1) filmy background of small coccobacilli; 2) absence of lactobacilli; and 3) individual squamous cells covered by a layer of coccobacilli, particularly at the margin (clue cells).

In this age when cost efficiency seems so important, the contribution of the Pap smear in the initial evaluation of pregnant patients should be seriously considered. Since both the Pap smear and Gram stain have close predictive values, duplication of tests could reasonably be avoided in most patients. Because $\mathrm{BV}$ is a vaginal rather than a cervical infection, the addition of a well-performed vaginal component to the routine cervical/endocervical smear in pregnant women will improve Pap smear sensitivity. Cytotechnologists should be well-informed of the diagnostic criteria for a shift in vaginal flora as outlined by TBS.

The Pap smear should be performed at the first prenatal visit regardless of the duration of pregnancy to establish the presence or absence of SIL, STD, and BV, all of which represent a risk to the fetus and the mother. This initial smear will not only establish a baseline at the first prenatal visit but may also be the only opportunity to diagnose SIL in patients with poor compliance. All these conditions can be followed safely and accurately throughout pregnancy by repeated Pap smears.

\section{References}

1. Cramer DW. The role of cervical cytology in the declining morbidity and mortality of cervical cancer. Cancer 1974;34:2018-2027.

2. Kaminski PF, Lyon DS, Sorosky JI, Wheelock JB, Podczaski ES. Significance of atypical cervical cytology in pregnancy. Am J Perinatol 1992;9:340-343.

3. Guerra B, De Simone P, Gabrielli S, Falco P, Montanari G, Bovicelli L. Combined cytology and colposcopy to screen for cervical cancer in pregnancy. J Reprod Med 1998;43:647-653.

4. Haam Von E. The cytology of pregnancy. Acta Cytol 1961;5:320-329.

5. Holmquist ND, Marion D. The cytology of early abortion. Acta Cytol 1967;11:262-266.

6. Khan AA, Ahmad S, Rizvi R. An increased incidence of an androgen type cell in vaginal smears of pregnant women carrying female foetus: possible significance. Acta Cytol 1976;20:347-348.

7. Blake RL Jr, Gay JW, Brown S, Smith W. Does evidence of inflammation on Papanicolaou smears of pregnant women predict preterm labor and delivery? J Am Board Fam Pract 1992;5:555-563.

8. Blake RL Jr, Dilger S, Ingram E, Gay JW. Cervical inflammation and preterm delivery in pregnant women with a history of preterm delivery. J Am Board Fam Pract 1994;7:465-471.

9. Chang-Claude J, Schneider A, Smith E, Blettner M, Wahrendorf J, Turek L. Longitudinal study of the effects of pregnancy and other factors on detection of HPV. Gynecol Oncol 1996;60:355-362.

10. Michael CW, Esfahani FM. Pregnancy-related changes: a retrospective review of 278 cervical smears. Diagn Cytopathol 1997;17:99-107.

11. Economos K, Perez Veridiano N, Delke I, Collado ML, Tancer ML. Abnormal cervical cytology in pregnancy: a 17-year experience. Obstet Gynecol 1993;81:915-918.

12. Jain AG, Higgins RV, Boyle MJ. Management of low-grade squamous intraepithelial lesions during pregnancy. Am J Obstet Gynecol 1997;177: 298-302.

13. Apgar BS, Zoschnich LB. Triage of the abnormal Papanicolaou smear in pregnancy. Prim Care 1998;25:483-503.

14. Londo R, Bjelland T, Girod C, Glasser M. Prenatal and postpartum Pap smears: do we need both. Fam Pract Res J 1994;14:359-367.

15. Danos M, Holmquist ND. Cytologic evaluation of decidual cells: a report of two cases with false abnormal cytology. Acta Cytol 1967;11: 325-330.

16. Benoit JL, Kini SR. “Arias-Stella reaction"-like changes in endocervical glandular epithelium in cervical smears during pregnancy and postpartum states-a potential diagnostic pitfall. Diagn Cytopathol 1996;14:349-355. 
17. Frank TS, Bhat N, Noumoff JS, Yeh I-Tien. Residual trophoblastic tissue as a source of highly atypical cells in the postpartum cervicovaginal smear. Acta Cytol 1991;35:105-108.

18. Kurman RJ, Solomon D. Descriptive diagnoses. In: Kurman RJ, Solomon D, editors. The Bethesda system for reporting cervical/ vaginal cytologic diagnoses. New York: Springer-Verlag; 1994. p $12-17$.

19. Diallo MO, Ettiegne-Traore V, Kouadio J, Brattegaard K, Makke A, Van Dyck E, Laga M, DeCock KM. Sexually transmitted and human immunodeficiency virus infections in women attending an antenatal clinic in Abidjan, Cote d'Ivoire. Int J STD AIDS 1997;8:636-638.

20. De Campos DA, Nougueira A, Magalhaes F, Bayer P, Monteiro J, Lameirao A, De Oliveira JM. Inflammatory smears in cervicovaginal cytology. A finding meaning infection? Acta Med Port 1997;10:637641.

21. Lanouette JM, Puder KS, Berry SM, Bryant DR, Dombrowski MP. Is inflammation on Papanicolaou smear a risk factor for preterm delivery? Fetal Diagn Ther 1997;12:244-247.

22. Bedrossian UK, Fairfax MR, Ayers M. Pap smear follow-up of mucopurulent exudate as a prognosticator of a negative pregnancy outcome. Diagn Cytopathol 1999;21:00-00.
23. Hillier SL. Diagnostic microbiology of bacterial vaginosis. Am J Obstet Gynecol 1993;169:455-459.

24. Mass SB, Brennan JP, Silverman N, Van Hoeven KH. Association between a shift in vaginal flora on Papanicolaou smear and acute chorioamnionitis and preterm delivery. Diagn Cytopathol 1999;21:7-9.

25. Kurki T, Sivonen A, Renkonen OV, Savia E, Ylikorkala MP. Bacterial vaginosis in early pregnancy and pregnancy outcome. Obstet Gynecol 1992;80:173-177.

26. Narcio Reyes ML, Casanova Roman G, Galindo Saenz J, Castelazo Morales E, Beltran Zuniga M. Utility of the Papanicolaou smear in the diagnosis of bacterial vaginosis. Ginecol Obstet Mex 1994;62:52-56.

27. Platz-Christensen JJ, Larsson PG, Sundstrom E, Wiqvist N. Detection of bacterial vaginosis in wet mount, Papanicolaou stained vaginal smears and in Gram stained smears. Acta Obstet Gynecol Scand 1995;74:67-70.

28. Davis JD, Connor EE, Clark P, Wilkinson EJ, Duff P. Correlation between cervical cytologic results and gram stain as diagnostic tests for bacterial vaginosis. Obstet Gynecol 1997;177:532-535.

29. Prey M. Routine Pap smears for the diagnosis of bacterial vaginosis. Diagn Cytopathol 1999;21:10-13. 